\title{
Dynamic simulation as a tool to improve the efficiency of energy systems. Applications in the steel industry.
}

\author{
T. Henrion ${ }^{1, \mathrm{a}}$, A. Werner ${ }^{2}$, R. Kitzberger ${ }^{1}$, and M. Haider $^{2}$ \\ ${ }^{1}$ Austrian Institute of Technology, Energy Department, Giefinggasse 2, 1210 Vienna, Austria \\ ${ }^{2}$ Vienna University of Technology, Institute for Energy Systems and Thermodynamics, \\ Getreidemarkt 9/E302, 1060 Vienna, Austria
}

\begin{abstract}
To answer the need in reducing the amount and costs of the energetic consumptions in large industries, improvement methods mostly based on stationary considerations are being used today. It is difficult with such approaches to consider potentials hidden in time dependent effects. The batch operated processes of an Integrated Iron and Steel Plant (IISP) typically show time dependent behaviour. Therefore, dynamic considerations are used in this paper to increase the efficiency of energy systems (steam and hot water networks) in a European IISP. This allows the consideration of potential improvements not only through modifications of the process design and operating conditions but also through optimized control parameters, and enhancement of the transient operation procedures.

This paper describes an improvement procedure for the considered energy systems. The physical modelling of all main components (sources, network piping, valves and control devices), is carried out with the simulation program APROS. The potential use of the physical dynamic models is then illustrated by a practical example, which deals with the operating conditions enhancement of a steam turbine. Finally, the application range of the developed simulation models is discussed. Especially, their further utilization for the implementation of model predictive control is outlined.
\end{abstract}

\section{Introduction and motivation}

The actual needs to further reduce the consumption of energy intensive industries leads to inquire some new ways in order to analyze and optimize new and existing processes. In the general procedure of the process synthesis, a concept is developed to fulfill some specific process requirements. Different alternative designs are created. The evaluation and optimization of the process alternatives leads to the choice of the most interesting one in terms of product quality and profitability [1].

For the alternative generation and the simulation of the process parameters different methods can be utilized. The simplest one uses a combination of empirical linear correlations to assess future unit performances. The use of thermodynamic correlations leads to more accurate physical simulation of the unit. These considerations assume a steady-state operation of the considered units. In order to improve this simulation accuracy and consider dynamic behavior of the processes, the time

\footnotetext{
a e-mail : thibault.henrion@ait.ac.at
} 
dependent formulation of the heat-, mass- and momentum-balance equations have to be considered by the process simulation. This last approach is more time consuming and intensive in calculation efforts, but the latest developments of simulation programs and computer speed allow always more applications of the dynamic simulation for larger systems [2].

Process modeling is nowadays widely used for the development of new process design. Especially dynamic simulation of transient operations helps the process designer to gain detailed knowledge on the developed process and deliver better optimized technical solutions. On the other hand, the detailed behavior of already operating process units, even if there are well documented, are often not completely clear to the operators because of missing information, especially dynamic behavior.

This paper describes the use of dynamic simulation in the case of an existing Integrated Iron and Steel plant (IISP). It shows, how solutions for improving operation profitability, by reducing the energy costs and increasing unit operability can be analyzed for existing plants through a dynamic simulation tool.

The work focuses on the utilized method through one specific application example from the steam distribution network simulation: the inlet steam parameter of an Energy recovery steam turbine are very variable and often differ from the equipment design requirements. This causes some droplet erosion problems on the blades of the last turbine stage, leading to higher maintenance costs. The paper describes how solutions for this issue are inquired with the help of dynamic simulation. It also shows the extent of possible findings by describing briefly further results, obtained for both the steam and hot water networks simulations.

\section{Description of the analyzed energy systems}

The dynamic modelling is applied to two energy networks of an integrated steel works: a steam network and a hot water network.

\subsection{Steam distribution network}

This section describes the main steam consumers and suppliers and their behavior. The main control mechanisms of the steam parameters are also explained. In order to characterize the system behavior, process data have been analyzed. The main outcomes of this characterization are exposed here.

Fig. 1 shows a scheme of the inquired steam network. The pipes are operated with a pressure of approximately 18 bars gauge (barg), and a temperature varying from $320^{\circ} \mathrm{C}$ to the condensing temperature of about $210^{\circ} \mathrm{C}$.

Most of the consumers are showing a relative constant consumption during the day. A consumption increase is observed seasonally in winter, as heat tracing is used for different purposes. Only the internal steam consumers of the steel mill present large and fast daily variations. The vacuum pumps of the secondary metallurgy processes, as well as the water spray cooling of converter gas require some large quantities of steam within few minutes for period of about 15 to 20 minutes.

The steam supply is mostly assured by the power plant which exports superheated steam (with approximately $300^{\circ} \mathrm{C}$ ). This steam comes from the steam turbine extraction and regulates the network pressure around the power plant (Pipes 1, 2 and 3 on Fig. 1).

Waste heat is recovered within the IISP, it is transformed into steam and injected into the considered network. About one third of the total annual steam demand is supplied by waste heat steam producers. There are three major producers within the steel plant. The largest one - the "basic oxygen furnace steam generators" - uses the heat of the Converter gas to produce steam in the steel mill (see Fig. 1). As the converter process is operated in batch, steam is produced within certain operation periods in large quantities. In order to regulate this unsteady production and keep a constant pressure in the steam network, a steam storage system (Ruth's accumulator type) is installed after these producers. A complex control system regulates the pressure in the steam generators and in 


\section{$2^{\text {nd }}$ European Energy Conference}

the storage between 18 and 30 barg. It operates a control valve at the outlet of the storage, which reduces steam pressure from the storage to the network level. The steel mill steam producers are equipped with safety valves which open at pressures above 31 barg. The produced steam is saturated. When the steel mill produces more steam than required for its own consumption, saturated steam is exported through pipe 7 to the "heat dispatching" plant.

The next significant waste heat recovery steam generators are the pusher furnaces. Their production is not constant and depends on the load of the reheating furnaces. The steam throughput can vary from half load to full load within half an hour. The produced steam is superheated to temperatures of about $320^{\circ} \mathrm{C}$ and is directly exported into the steam network.

The last waste heat producer is the walking beam furnace. Its production stays generally constant and steam is exported in saturation conditions to the steam network.

To prevent the network pressure from attaining too high levels, and for the protection of the equipment, the steam system is equipped with different safety mechanisms:

- a blow-off valve located in the heat dispatching area, which can be opened when the production of waste heat steam becomes higher than the network demand.

- a by-pass at the waste heat steam generators of the pusher furnaces, which allows to blow-off hot flue gas in order to limit the steam production and avoid pressure peak in the steam network.

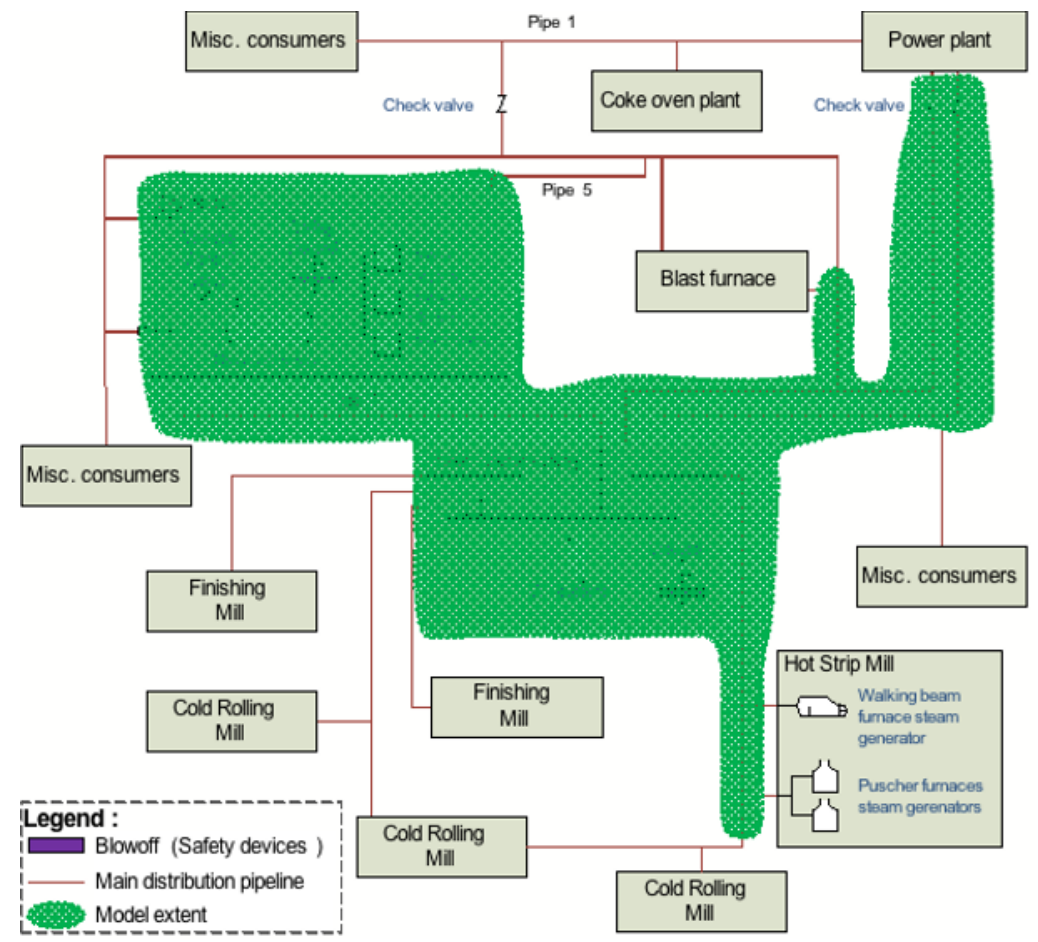

Fig. 1. Schema of the steam distribution system

Even if the pipes are insulated, heat losses through the pipes wall are decreasing the superheated steam temperature. Large transportation distances between the producers and consumers (ex: Pipe 2 is approximately $2 \mathrm{~km}$ long) are responsible for steam temperature drop; in some cases, where consumers are located far from the production points, saturated steam is delivered. In order to avoid water accumulations in the pipe due to condensation phenomena, steam traps are regularly positioned on the whole network.

The superheated steam temperature is regulated at the power plant and at the pusher furnace. Otherwise the steam temperature results from the mixing of steam with different qualities in the heat dispatching plant. The latter regulates through redirection of the steam flows in two steam headers 
the temperatures in the steam network. The plant also recovers energy from the steam that is internally used at a lower pressure through an Energy-Recovery Turbine ("ER-turbine" in Fig. 1).

The analysis of process data for selected operation days reveals that pressure peaks occur in the network when the delivery from the pipes 1 and 2 is low and the production of the pusher furnace is high. This is an indication for local steam excess in a part of the network (concerned units are the steel mill, heat dispatching, hot strip mill). On the other hand, the temperature of the steam entering the ER-turbine often falls under the specification of $250^{\circ} \mathrm{C}$. Often saturated steam is delivered to the turbine. This leads to a higher rate of droplet erosion on the turbine blades.

The steam network model should be able to reproduce those two phenomena in order to investigate improvement measures on these issues.

\subsection{Hot water distribution network}

The hot water distribution network dispatches heat within the IISP mostly for building heating purposes. However, the main consumer of the network is external to the site. This external client consumes about 80 to 90 percent of the heat supplied within the IISP. The heat is supplied within the plant mostly by low pressure (2-3 bar) steam condensing heat exchangers. A part of the supplied heat (about 15\%) comes from the exhaust gas of one of the power plant units. It can be considered as waste heat source.

The main instrument of the network operation is the main pump of the system. It regulates a pressure drop in the external client network. The temperatures in the network are regulated behind the steam heat exchangers. The adjustment of supplied heat to heat demand results from the variation of the main pump's mass flow. This demand shows a daily peak from $7 \mathrm{~h} 00$ to $22 \mathrm{~h} 00$ where the heat demand can be 2 times higher than during the off-peak.

\section{Apros}

APROS [3] is a simulation tool which is focused on dynamic simulation of thermal and nuclear power plants. It allows the modeling of 2-phase flow considering each phase separately (6-equation model [4]). A one dimensional discretization method of the pipes is used to solve the governing equations of fluid mechanics, [5] [6]. Boiling crisis can be taken into account. The possibilities of varying the models boundary conditions and modeling elaborated control systems makes this program quite appropriate for the purposes of this work.

GRADES is the graphical interface of APROS and allows a process flow diagram representation (see Fig. 2) [7].

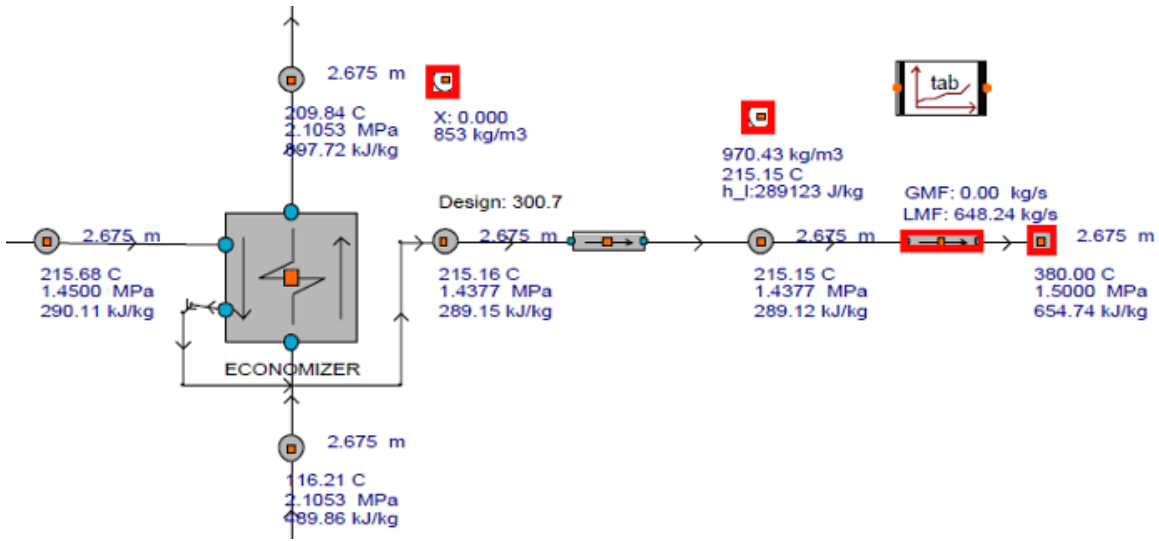

Fig. 2. View of the simulation interface GRADES 
The program has been chosen because it can simulate condensation phenomena inside steam pipes as well as in tanks (application for the steam storage). It allows an accurate simulation of vaporization in the steam storage vessels and the steam generators.

\section{Physical modeling and Validation}

By using the program APROS, models of the energy distribution networks have been developed. They are able to reproduce the unsteady behavior of the unit during up to a complete day of operation. Different models were used in order to answer several questions coming from the operating team and analyze the influence of process modifications on the whole systems.

\subsection{Simple steam pipe model}

A model of one of the transportation pipes between power plant and heat dispatching plant (pipes 1, 2) has been developed in order to characterize the energy demand of the pipeline during normal operation with different throughput and during shut-down and start-up operations. It reproduces the $2 \mathrm{~km}$ long pipe with its insulation and pressure drop. The modeled pipe is equipped with steam traps that are ideally removing the liquid phase from the steam flow. This model is validated by comparing simulated temperature and pressure drop along the pipe with measured data.

\subsection{Reduced steam network model}

\subsubsection{Modeling}

Only a part of the whole steam network is modeled, as process data and documentation is not available for each part of the system. The extent of the simulation (green dotted line on Fig. 1) is large enough to analyze the pressure peaks and the steam temperature before the ER-turbine.

The model includes:

- the steel mill with its different consumers, the steam storage, as well as a simplified steam producer that re-create the steam production of the waste heat boiler. Mass flow boundary conditions are used to model the production and consumption. The steam accumulator control loops are also accurately modeled thanks to special components from the simulation software APROS.

- The heat dispatching plant with its internal consumers. Especially the ER-turbine is modeled and equipped with a non-ideal water separator whose behavior approaches the performance of a real water separator (see performance curve in Fig. 3).

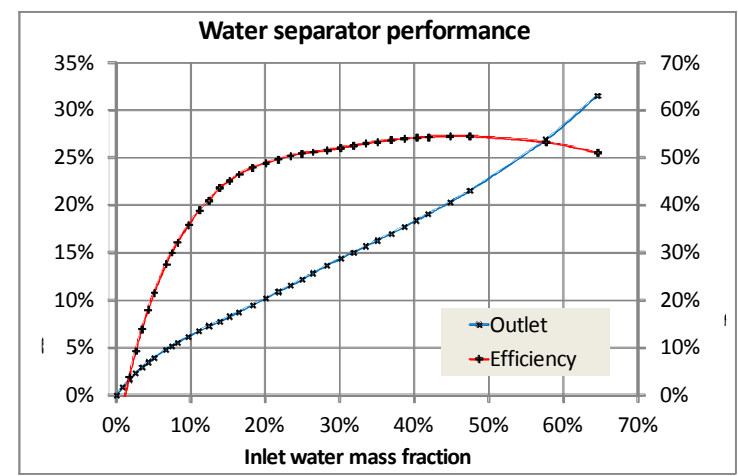

Fig. 3. Performance of the modeled non-ideal water separator 
- The productions of the hot strip mill steam generators (pusher furnaces, walking bean furnace) which are modeled with variable mass flow boundary conditions.

- Various other consumption points also modeled with variable mass flow boundary condition modules.

- The power plant, which is regulating the pressure at the beginning of the east pipes. In that case the steam inlet is modeled for both pipes with separate variable temperature and pressure boundary conditions. These boundaries equalize the measured process data. In that way of modeling the power plant, the role of the unit, which in reality compensates the demand gap between producers and consumers, can be well reproduced.

Steam trap are simulated at strategic places of the network to separate liquid from the gas flow. As the model includes much less steam trap than in the real installation and as those are modeled as ideal separators, the counting of the separated water gives only qualitative information about how much steam condensates in the network.

\subsubsection{Validation}

For the model validation, process data of a specific operation day are used. The model results (pressures, temperatures, mass flows) are compared with the measured data, and adjustments are made to the model until the required accuracy is reached.

The mass flows delivered by the power plant are particularly significant for the exactness of the model. The curves of Fig. 4 show a good approximation of the model even if few gaps remain for the pipe 3 .

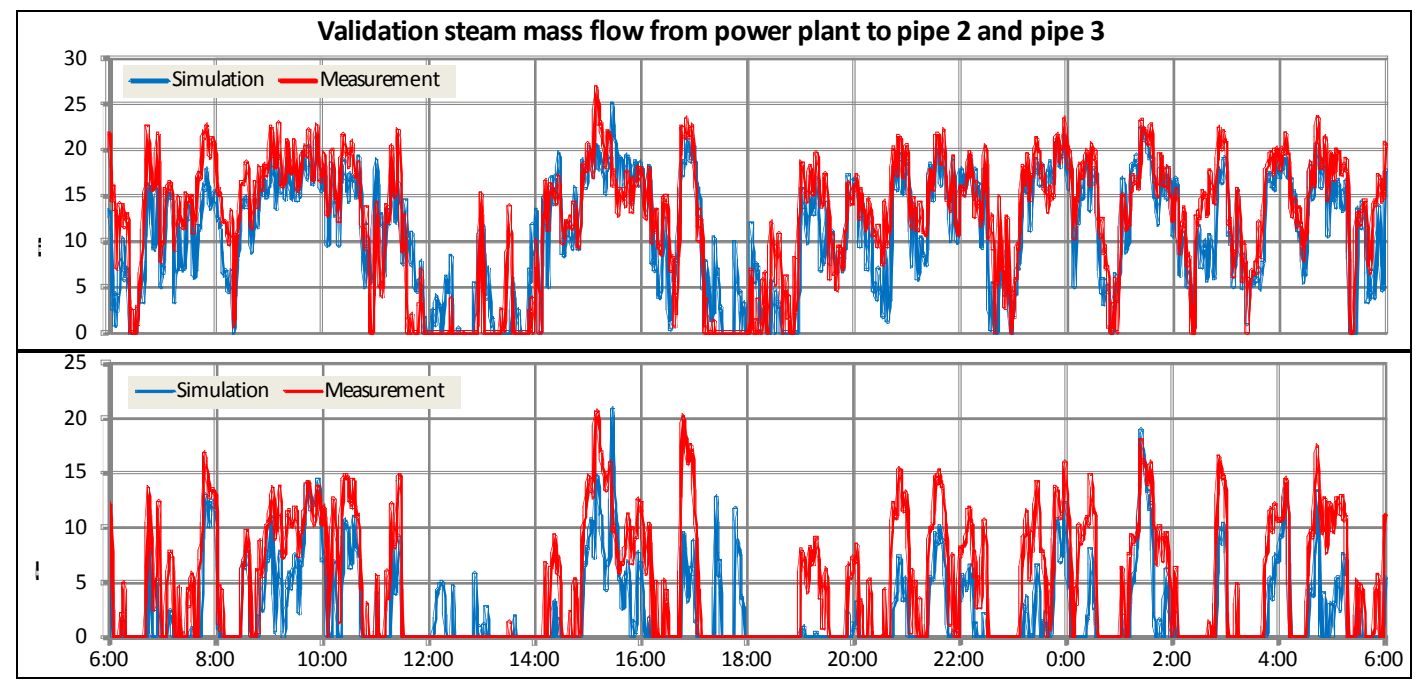

Fig. 4. Validation of the steam export from the power plant through the pipes 2 and 3

Further validations are made on:

- the pressure level in the heat dispatching: here higher pressure peaks are observed in the model. This is due to the reduced model extent. Actually the smaller modeled network volume is the reason why pressure peak due to a steam excess in the net trigger higher pressure peaks;

- the temperature in the heat dispatching: it shows relative good model accuracy;

- the steam storage pressure profile: it confirms good modeling of the storage control system;

- the mass flow out of the steam storage: it shows a good accuracy of the mass balance in the steel mill.

The validation generally demonstrates that the model can predict with good accuracy most of the network parameters; it can be generally used for further investigations. Specific model deviations like the pressure peaks have to be considered for the results interpretation. 


\section{$2^{\text {nd }}$ European Energy Conference}

\subsection{Hot water network model}

The modeling of the hot water network is easier, due to the presence of only one phase-flow in the pipes. The modeling and validation show similarly to the steam network that the dynamic model can reproduce the behavior of the real one with quite good accuracy. Heat losses, pressure losses, delivered heat flows, as well as the main pump behavior are modeled with a good accuracy.

\section{Simulation findings}

This section describes in details the analysis of the temperature and water mass fraction problem on the inlet of the ER-turbine. Additionally, further results are briefly explained in order to give an overview of the application range of the dynamic simulation tool.

\subsection{Steam system}

\subsubsection{Operating conditions of the ER-turbine}

For this investigation, possibilities to improve the operating conditions of the ER-turbine are analyzed with the help of the developed steam network model. 4 different network configurations (business cases) are simulated always with the same input process data of a complete operation day:

- $\quad \underline{\text { case } 0}$ is the validation case, the system without any improvement. It is the base case.

- In case1, the configuration of the steam distribution header in the heat dispatching is changed. The saturated steam flowing from the steel mill is mixed with superheated steam from the pipe 2 and 3 before it is injected into the header, which then supplies the turbine.

- In case2, the consumer cold rolling mill, which is supplied from pipe 8 and pipe 9, is only supplied from the pipe 8 . This measure allow more superheated steam from the pusher furnaces waste heat boilers to flow to the turbine

- case 3 combines the measures of case 1 and case2. The supply of superheated steam to the steam turbine can be maximized in that way.

The different configurations are tested with the steam network model. The simulation results are summarized in Table 1.

Table 1. Results of the case study on the ER-turbine parameter improvement

\begin{tabular}{|c|c|c|c|c|c|c|}
\hline & & & Case0 & Case1 & Case2 & Case3 \\
\hline \multicolumn{2}{|c|}{ Variation of the total condensation losses ${ }^{\text {(a) }}$} & $\%$ & - & 6,6 & $-11,5$ & $-10,6$ \\
\hline \multicolumn{2}{|c|}{$\begin{array}{l}\text { Variation of the average steam temperature } \\
\text { before the ER-turbine }\end{array}$} & ${ }^{\circ} \mathrm{C}$ & - & 14,6 & 3,1 & 51,1 \\
\hline \multirow{2}{*}{ Average water mass fraction } & Before turbine & $\mathrm{m} \%$ & 0,81 & 0,26 & 0,75 & 0,01 \\
\hline & After turbine & $\mathrm{m} \%$ & 6,20 & 4,41 & 5,93 & 1,35 \\
\hline
\end{tabular}

(a) : Variation to case 0

The simulated cases show that all measures bring improvement to the steam quality entering the turbine, however in different extents. Case1 allows a reduction of the water mass fraction after the turbine of about $30 \%$ in comparison to case 0 . The steam is injected to the turbine in average $15^{\circ} \mathrm{C}$ warmer than in case 0 . The measure of case 1 also causes more condensation in the whole steam network as colder steam is distributed to the consumers. The measure of case 2 shows only little improvement of the situation. The combination of case 1 and case 2 measures in case 3 shows the most significant improvement as the steam temperature is raised in average of about $50^{\circ} \mathrm{C}$. Condensation 
in the network is also reduced for case3. The profiles of the steam inlet temperature and the water mass fraction before and after the turbine are compared for case 0 and case 3 in Fig. 5. With an average outlet water mass fraction at the turbine outlet of about $1,35 \%$, the risks of droplet erosion on the turbine blades are considerably reduced by the last measure.

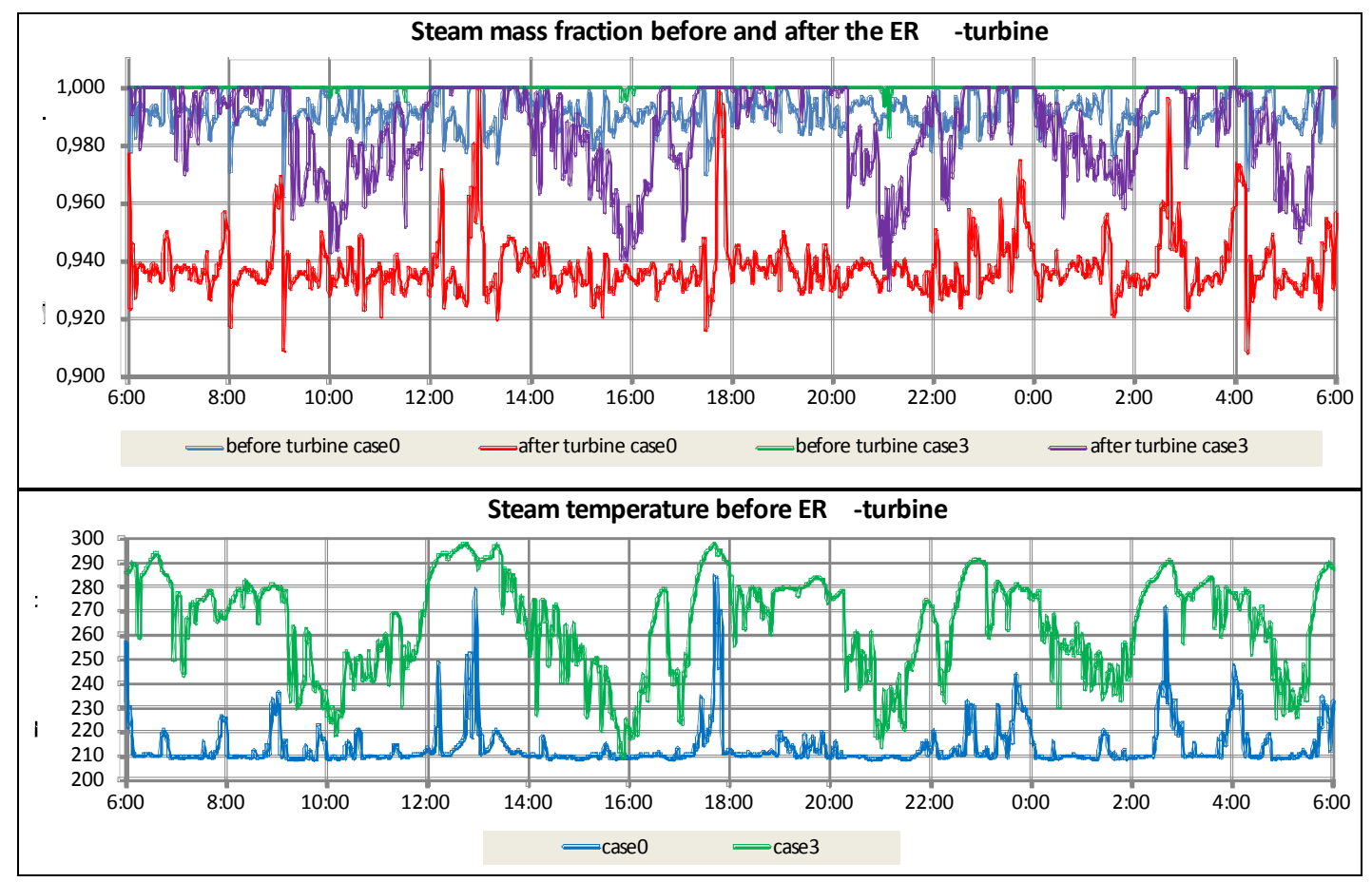

Fig. 5. Results of the case study on the steam turbine parameters

\subsubsection{Other results from the steam system analysis}

Parametric studies with the model of the simple steam pipe deliver information about the operation range within which steam can be transported under superheated conditions. The model also gives indications about the condensation rates during the transport of smaller steam mass flow.

The simulation of the stop and start procedure of the steam pipe is used to determine the energy demand of these operations. This information is useful to improve the annual operation planning of the pipe with regard to the steam throughput. Actually the operation with only one of both pipelines from power plant to heat dispatching (pipe 2 and 3) reduces considerably the heat losses. Moreover, thanks to the model, the start procedure of the pipe can be analyzed. This reveals that the warm-up time of the pipe can be reduced, thus reducing the energy demand for the starting operations.

The model of the reduced steam network helps to estimate the effects of some measures in order to reduce the pressure peaks. For example, the storage size can be varied, or some modified control parameter of the steam storage valve control loop can be tested. The simulation of these possible process improvements shows that the pressure peaks can be reduced best, with optimized control parameters of the storage control valve.

\subsection{Hot water network}

With the model of the hot water network, different measures to increase the net heat delivery capacity can be tested. By reducing the pressure losses in the network, water mass flow can be increased and thus more heat can be transported. The implementation of a new by-pass with specific 


\section{$2^{\text {nd }}$ European Energy Conference}

control sequence promises a significant reduction of pressure losses. The model was also used to optimize the heat recovery from a waste heat source.

\section{Conclusion and perspectives}

Through different application examples this paper showed how dynamic physical models can be used to improve energy efficiency and operability of complex energy systems. It was especially shown how steam temperature and water mass fraction can be predicted by the model for different improvement measures utilizing steam redirection. The better option on the operative point of view can be in that way identified.

The developed analysis method is based on the program APROS, which models the heat and mass transfer for one and two-phase flow. In order to better understand the systems behavior, an analysis based on process data is necessary to show the relation between consumers and producers and networks operation quality parameters. This first step helps to better define the inquired problems, it leads to the definition of the model requirements and boundaries. Model build-up and validation is realized in the present case (for existing units) with real process data, which help to reach a good accuracy of the model predictions. The validated models are used as tools to assess the effects of some improvement measures on the energy demand and operation quality parameters of the whole system. In that way all time dependent phenomena like pressure, heat flow and temperature peaks are considered.

The method can be applied like in the example to existing units but also for grassroots design of innovative energy system design like in [7], [8], [9] or [10]. The use of such models opens application perspectives for the development and implementation of complex control systems like in [11]. The use of predictive control algorithms can be inquired with the developed tool in order to realize a real time optimization of the considered energy systems. Further developed models can also be used for the training of operators to the unit behavior. It helps minimizing product and energy losses during shut-down and start-up operations, but also in emergency situations.

\section{References}

1. M. Tuomaala; Conceptual approach to process integration efficiency; Doctoral Dissertation ed. Helsinki: Helsinki University of technology ; (2007)

2. T. Henrion, "Dynamische Simulation als Tool zur Verbesserung der Effizienz von Energiesystemen “, Doctoral Thesis ed. Vienna: Vienna University of Technology (2012).

3. http://www.apros.fi/en/.

4. M. Hänninen, J. Ylijoki ; The constitutive equation of the APROS six-equation model (2007).

5. N.I.Kolev ; Multiphase Flow Dynamics 1 (Springer, 2002).

6. S. V. Patankar ; Numerical Heat Transfer and Fluid Flow; Series in Computational Methods in Mechanics and Thermal Sciences ; Hemisphere Publ. Corp., Washington (1980).

7. T. Henrion, K Ponweiser, D. Band, T. Telgen ; Dynamic simulation of a solar power plant steam generation system; Simulation Modelling Practice and Theory (2012).

8. M. Paananen, T. Henttonen, Investigations of a Long-Distance 1000 MW Heat transport System with APROS Simulation Software, in 20th International Conference on Structural Mechanics in Reactor technology, Espoo (2009).

9. M. Heim, T. Ferrand, F. Kluger, Simulation der Dynamik von Steinkohledampferzeugern beim Anfahren, im Lastbetrieb und bei Betriebsstörungen, Sichere und nachhaltige Energieversorgung (2010).

10. M. M. Schlagenhaufer, Simulation des Dampf-Wasserkreislaufs und der Sicherheitssysteme eines High Performance Light Water Reactors, KIT Scientific Reports 7582 (2011).

11. R. Schimon, Analyse des dynamischen Verhaltens gasförmiger Energieträger in multiverzweigten Rohrnetzwerken, Doctoral Thesis ed. Vienna: Vienna University of Technology (2011). 